\title{
A QUALITATIVE STUDY DISCOVERING THE COMMON MEDICATION-THERAPY PROBLEMS IN PATIENTS WITH TYPE 2 DIABETES MELLITUS (T2DM) IN INDONESIA
}

\author{
RETNO WAHYUNINGRUM ${ }^{1}$, DJOKO WAHYONO ${ }^{2 *}$, MUSTOFA MUSTOFA ${ }^{3}$, YAYI SURYO PRABANDARI ${ }^{4}$
}

Doctoral Student, Faculty of Pharmacy, Universitas Gadjah Mada, Yogyakarta, Indonesia. ${ }^{2}$ Department of Pharmacology and Clinical Pharmacy, Faculty of Pharmacy, Universitas Gadjah Mada, Yogyakarta, Indonesia. ${ }^{3}$ Department of Pharmacology and Therapy, Faculty of Medicine, Universitas Gadjah Mada, Yogyakarta, Indonesia. ${ }^{4}$ Department of Public Health, Faculty of Medicine, Center of Health Behavior and Promotion, Universitas Gadjah Mada, Yogyakarta, Indonesia. Email: wahyono_djoko@yahoo.com

Received: 01 March 2017, Revised and Accepted: 13 April 2017

\section{ABSTRACT}

Objective: The aim of the overall study was to develop a model to improve the quality of counseling practice in pharmacies. The research question addressed in this substudy was to identify the medication therapy problems (MTPs) of type 2 diabetes mellitus (T2DM).

Methods: A total of 42 participants were interviewed between November 2015 and May 2016 through semi-structured surveys. Face-to-face interviews were conducted with patients who visited the internal clinic in the three general hospitals at Yogyakarta. It emphasized on the patient's drug-related experiences, knowledge, perceptions, problems, and actions. The analysis was done thematically using the interpretative phenomenological analysis technique.

Results: The average age of participants was 57.7 years, and more than half were women (55.5\%). The most common therapy-related problems are related to individual factors, in term of inappropriate lifestyle choices, which include smoking, having a body mass index value over 25 , lack of exercise, lack of knowledge about the nature of their disease, some did not know about the influence of foods on blood glucose level, the effect of the medicines on the disease and/or complications. The interviewees had realized that psychological stress enhanced their blood glucose.

Conclusion: Pharmacists need to pay attention to the management of non-pharmacological when giving advice to patients with T2DM.

Keywords: Type 2 diabetes mellitus, Interviews, Medication-therapy problems, Patient perspective, Counseling, Non-pharmacological therapy.

(C) 2017 The Authors. Published by Innovare Academic Sciences Pvt Ltd. This is an open access article under the CC BY license (http://creativecommons. org/licenses/by/4. 0/) DOI: http://dx.doi.org/10.22159/ajpcr.2017.v10i7.18217

\section{INTRODUCTION}

According to the basic health research in Indonesia (Riskesdas), the prevalence of diabetes mellitus (DM) increased from 1.1\% (2007) to $2.1 \%$ (2013). DM was observed more in people with the age range 55-64, who are females, educated, live in urban areas, entrepreneur, and have a high ownership index quintile. DM is included in the 7 most diseases causing death [1].

DM is a common disease, but each patient requires unique treatment. The medication to control blood glucose levels in type 2 diabetes are meal planning, weight loss, and exercise. They are insufficient to lower blood glucose levels closer to normal range. Therefore, it is necessary to combine it with antidiabetic agents. Oral hypoglycemic agents intended to keep blood glucose levels close to normal, thus decreasing the risk of long-term complications and improving the quality of life.

Interestingly, many patients with type 2 diabetes mellitus (T2DM) have poor glycemic control based on the preliminary study. The American Diabetes Association explained that problems were inappropriate in drug selection and dosage [2]. In addition, adherence issues also contribute to poor glycemic control. It is not only the use of drugs but also on lifestyle perform therapy which includes medical nutrition therapy, regular physical activity, adequate rest, behavioral support, smoking cessation, and avoidance of all tobacco products.

This study ensured the medication-related problems through the interview. We considered that interviewing the patient was useful to collect data to augment medication reviews related to the identification of medication therapy problems (MTPs). Patients can describe and elaborate on their medication- and illness-related experiences, thoughts, actions, and their problems [3]. Several other studies identify drug-related problems retrospectively $[4,5]$. The research objective is to identify MTPs in outpatients with type 2 diabetes.

\section{METHODS}

The primary data were obtained from interviewing participants on the basis of a semi-structured interview guide. Secondary data, that is, glycosylated hemoglobin (HbA1c), fasting blood glucose level, lipid profile, weight, and blood pressure of patients taken from medical records as well as the prescribed medication. Interview sessions were audio-recorded.

\section{Study design}

A descriptive study conducted to ascertain the diabetes MTPs. Face-toface interviews were conducted to collect data from each participant.

\section{Setting}

The study was conducted in several general hospitals, such as regional Public Hospitals of Sleman and Wates Kulon Progo, representing government hospitals, and Bethesda Hospital-private managed. All public hospitals are located in the province of Yogyakarta have an internal medicine service. The first hospital is located in the district, which has the most population of the province; the second represents the hospital in rural areas; and the latter one is located in the center of the city. 


\section{Sample and recruitment}

The outpatient with type 2 diabetes was the target population of this study. Participants were recruited by a purposive sampling technique. In qualitative research, there are no standard rules in determining the sample size for the interview, but there is general agreement that the sample size should be determined when the data saturation was reached [4]. The eligibility criteria were male and female, diagnosed with T2DM (written in the medical record), getting oral hypoglycemic agents or insulin, agreeing to participate in the study by signing the consent form. If the patient had hearing loss, unable to communicate, and dementia were excluded.

In Sleman and Wates General Hospitals, participants were recruited in the outpatient clinic's waiting room. While the other hospitals recruitment participants had been held in pharmacy's waiting room. If an interview was not completed, it was continued when they were waiting for a prescription service or in other times by appointment.

\section{Data collection}

The data were collected by the first author, face-to-face with patients in the waiting room or other agreed locations (such as patient's home and mall). The interview with Sleman General Hospital's patients was conducted between November and December 2015, Bethesda Hospital between January and February 2016, Wates General Hospital between April and May 2016.

An hour was allocated for an interview, but the duration of interview depended on the depth of each patient's response, in an average of 25-40 minutes, not including the process to get the informed consent. The interview guide describes in Table 1.

\section{Interview guide}

The interview guide was designed to ascertain in-depth knowledge about each patient's perceptions experience, judgment, action, and the problems associated with the treatment and their disease. The interview guide was used to frame the topic of the interview. The combination of open- and closed-ended questions was formulated focusing on domains, including medicine- and illness-related knowledge, medication compliance, social support, psychological conditions, use of alcohol and tobacco, and the symptoms of other diseases.

\section{Medication therapy problems (MTPs) documentation}

As reported by Adusumilli and Adepu [3], as many as 14 systems for classifying drug-related problems, published in the international literature. To ensure a reliable and consistent documentation, identification of problem drug therapies based on a system developed by Pharmaceutical Care Network Europe Version 6.2. It was first developed in 1999 and had been revised several times. The system was also used to document information related to the treatment of problems in the process of pharmaceutical care. This system contains the codes for the problems, causes, and intervention separately. Some studies using this system to determine the nature, prevalence, and incidence of treatment-related problems $[7,8]$. A principal investigator using a checklist was developed by Roozendaal and Krass [9] to explore medication-related problems.

\section{Data analysis}

All audio recording were stored in digital format, in a secure computer network drive. The results of the interview transcribed into the interview guide, either verbatim or with the words of the investigator herself. The interview transcript was encoded by open code 4:03, and the initial coding structure using the "Medication adherence framework" was developed by Wiener et al. [10]. Data were encoded into multiple dimensions. Then, the inductive approach was used to identify the emergence of a second code and concepts in each dimension to explain the phenomenon.

\section{Ethical approval}

The study was approved by the Medical and Health Research Ethics Committee Faculty of Medicine Gadjah Mada University - Dr. Sardjito Public Hospital (Ref: KE/FK/576/EC/2015).

\section{RESULTS}

\section{Participant characteristics}

A total of 46 patients were eligible to the study criteria and signed a consent form, mostly female (61\%). The average age was 57 . Around, 42 participants completed the interview; there were 23 participants who successfully checked glycemic control. Eleven participants had HbA1c $>7 \%$. Nine of the eleven participants with poor glycemic control were analyzed to explore the issues that cause blood glucose was unregulated. The study design can be seen in Fig. 1.

There were three participants lost the interview because of rush and did not meet the investigator at the agreed time. Not all participants were willing to take a blood sample due to sore, fear, and were taking antiplatelet medications, so they worried about longer bleeding time. Characteristics of focus group participants $(n=23)$ were presented in Table 2.

Most participants had hereditary factors, which contribute to the emergence of the disease. Only one participant (male) who reported his disease as a result of unhealthy lifestyle, for example, often got stress at work or many things in daily life that cause psychological effects, irregular meals, and lack of exercise. There were eight participants that lived with diabetes for more than 10 years (range 10-33 years); one participant (male) was newly diagnosed, the other two were less than a year, 12 participants that had experienced DM were between 1 and 10 years. Around, 11 female participants had poor glycemic control. Not all participants with diabetes duration of more than 10 years had poor glycemic control.

Several different themes were identified. The majority of participants informed that they would adhere to medication prescribed. The participants newly diagnosed stated that they did not know much about the disease and how to manage it. Those who suffered with diabetes for long agreed that they have been able to control their lifestyle, including diet, exercise, and smoking. Some patients were less successful in treating the diabetes, particularly because of stress.

Knowledge and behavior associated with diabetes and medicines In general, the patients recognized the function, dosage, frequency, time, and method of medicine use and storage of drugs, but most of the participants did not understand the name, side effects, the ways to handle adverse effects, and drug interactions. Some patients had taken herbal medicines in decoction to assist lower blood glucose, but most of them did not believe that the traditional medicines could lower blood

Table 1: Content of interview guide patients [6]

\begin{tabular}{ll}
\hline Main topic & Subtopic \\
\hline $\begin{array}{l}\text { Knowledge and behavior in relation to } \\
\text { disease and drugs }\end{array}$ & $\begin{array}{l}\text { The use of drugs (drug name, dosage, knowledge of the effect of the drug), perception of the use of } \\
\text { drugs, side effects (experience, consent about adverse effects, speculation about side effects), other } \\
\text { problems with medicine use, self-regulation of medicine use (rational reasons, explanation) }\end{array}$ \\
$\begin{array}{l}\text { Perception of disease and health as well } \\
\text { as strategy }\end{array}$ & $\begin{array}{l}\text { Causes of diabetes (smoking, lack of physical activity, food, genetics, and others), strategies to stay } \\
\text { healthy, the ways to deal with disease and drug-related problems, the current state of health, social } \\
\text { interaction } \\
\text { Caily life with disease and drugs }\end{array}$ \\
\hline
\end{tabular}


Table 2: Demographic and clinical characteristics of participants $(n=23)$

\begin{tabular}{ll}
\hline Patient characteristics & N \\
\hline Gender & \\
Male & 11 \\
Female & 12 \\
Age & \\
$30 \mathrm{~s}$ & 2 \\
$40 \mathrm{~s}$ & 2 \\
$50 \mathrm{~s}$ & 9 \\
$60 \mathrm{~s}$ & 8 \\
70s & 2 \\
Marital status & 23 \\
Married & 0 \\
Unmarried/divorced/bereave & \\
Employment & 9 \\
Work & 14 \\
Retired/not working & 1 \\
Latest education & 10 \\
Elementary school & 5 \\
Junior/senior high school & 6 \\
Diploma & 1 \\
Bachelor & 0 \\
Master & Mean or N \\
Doctor/medical/law & 11.2 (0.2-33) \\
\hline Patient characteristics & 7 \\
\hline Duration of diabetes (n=22): Years (range) & 5 \\
Primary treatment & 11 \\
Insulin injections and oral antihyperglycemic & 7.9 (5.8-12.9) \\
Insulin injections & \\
Oral antihyperglycemic \\
HbA1c: \% (Range) & \\
\hline
\end{tabular}

HbA1c: Glycosylated hemoglobin

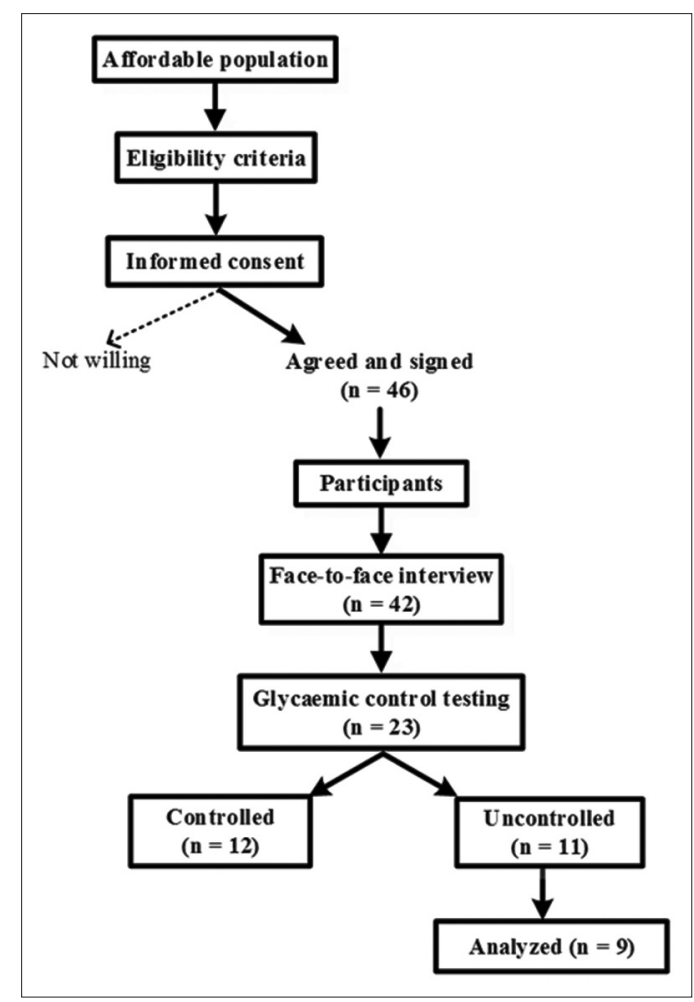

Fig. 1: Overview study design

glucose significantly compared with either insulin or oral antidiabetic agents.

\section{Medication adherence}

The patients would averagely adhere to take their medicines or inject their insulin. There was a patient who had tried to stop taking the drugs because she felt her condition well-regulated. During withdrawal, she did not control the diet or even exercise. This made her realizes that diabetes cannot be cured but can be controlled, among others, by taking drugs. Such experience was valuable for the patients. The desire to cure was a motivation for most patients to always take medications or inject insulin despite boredom. They believed that the medicines had given more benefits than the risk of adverse effects. They assumed that their medicines had actually passed through various stages of both pharmacological and toxicological studies, to assure the efficacy and safety.

\section{Knowledge practice on disease}

Only few patients claimed that they suffered diabetes because of family history, whereas most reported that uncontrolled diet and lack of physical activity triggered the disease, so they were currently practicing a healthy lifestyle by regulating diet and trying to be more active in their daily lives. In general, patients had learned that discipline in managing their lifestyle and taking medication could enhance their glycemic control. They considered that regular physical activity was effective to do so, such as, by gardening in the afternoon daily, playing badminton, cycling, walking, and gymnastics, particularly those with physical ability. However, some patients were not able to do such extra physical activities because of non-conducive health condition. Having no time for exercise and laziness were particular concerns for the investigator. HbA1c in active patients and inactive ones was different, although the results of assessment indicated that the level of medicine- and illnessrelated knowledge as well as medication adherence were similarly good. Besides, lack of discipline in exercise and diet, psychological factors caused uncontrolled blood glucose. It was reported that excessive job stress and anxiety could increase blood glucose level. The more severe the responsibility, the higher stress underwent by patients. Most patients stated that they could not overcome it. In the social lives, all patients expressed satisfaction over the support and understanding given by the family. There were some patients who embarrassed if others knew that they were taking a lot of drugs. They were also afraid of the judgment by others about the severity of disease suffered. However, some patients were not burdened when injecting insulin in front of their relatives and friends. The patients' awareness to visit the doctor regularly and perform blood test was very high because the desire to be healthy was so great. There was a patient reporting that when at a pilgrimage, he never injected insulin but the blood glucose was well-regulated. This was interesting for the investigator to probe. When in the holy land, his physical activities increased with the routines of worship performed. In view of foods consumed, the menu was controlled for meeting nutritional balance. It can be said that his psychological condition was stable because he performed more spiritual activities so that he was away from the depressed feeling. Arriving home, he was busy in work, had uncontrolled diet, and no time to exercise, thus causing his blood glucose uncontrolled despite the adhered to the injection of insulin. The patient's knowledge about diabetes was closely related to stress management. The more diabetesrelated knowledge, the higher understanding on stress management. Stress could increase their blood glucose level.

Education would lead to the effect on patients' mindset and perception on the disease management. The education level determined whether a patient was easy to understand the information provided. The patients' office time would affect them to think a way to control their stress. Those who did not work or were retired had more time to think how to cope with stress. The family's or friend's support can also reduce stress. By the support, they took medicine and managed their lifestyle more regularly. Most patients stated that the role of a family member to remind and pay attention made them motivated to live a healthy lifestyle and minimize the psychological stress. They had known that complications arose if their blood glucose levels were uncontrolled. 
Table 3: The MTPs in T2DM patients and the causes

\begin{tabular}{|c|c|}
\hline Problem & Cause \\
\hline 1. The clinical effect of the treatment is not as & 1. Patient forget to take the pills or use insulin \\
\hline expected (regulating plasma glucose level) & 2. Felt better \\
\hline 2. The patient suffers from adverse drug reaction at normal dose & 3. Patient not aware of medication change \\
\hline \multirow[t]{4}{*}{$\begin{array}{l}\text { 3. Nothing seems wrong in the treatment, but patient is unhappy } \\
\text { about it }\end{array}$} & $\begin{array}{l}\text { 4. Patient stored insulin inappropriately, especially along the way from hospital } \\
\text { to his/her home }\end{array}$ \\
\hline & $\begin{array}{l}\text { 5. Patient has disease which affects the result of laboratory test, such as anemia, } \\
\text { chronic kidney disease }\end{array}$ \\
\hline & $\begin{array}{l}\text { 6. The behavior of the patient related poor eating pattern, lack of physical } \\
\text { activity, smoking status, and psychological stress }\end{array}$ \\
\hline & 7. Lack of knowledge about the nature of her/his disease \\
\hline
\end{tabular}

MTPs: Medication-therapy problems, T2DM: Type 2 diabetes mellitus

Some patients had diabetes complication. Thus, it was necessary to build a strategy to prevent the disease from being complicated.

\section{Smoking status}

Most of the participants with poor glycemic control were not an active smoker. Nevertheless, a number of them had body mass index $>25 \mathrm{~kg} / \mathrm{m}^{2}$.

\section{Daily life with diabetes}

The daily life of patients with diabetes was as usual as those without diabetes in doing their activities. A homemaker who must cook for her family also prepared a specific menu for herself, which was different from that for other family members. Almost, all the patients did not perform a self-monitoring of blood glucose, but some carried out an experiment by themselves to find out the effect of food on blood glucose alteration. The results of the trial and error were used to regulate a safe portion of diet. A number of patients experienced some adverse drug events or symptoms of other diseases, but based on their reports, it did not disturb and only appeared occasionally. The symptoms disappeared when they took some medication prescribed. Productive age patients asserted that there was no problem in their sexual lives, but some reported their sexual ability decreased. Table 3 summarizes the problems and causes associated with MTPs.

\section{DISCUSSION}

Findings from this qualitative research study showed that there are a number of reasons for poor glycemic control, including poor concordance (persistent adherence) with lifestyle changes, stressful live events, and inadequate exercises. A number of previous studies reported that the diabetes therapeutic target not met due to genetic factors, lower economic status, and psychological factors. Poor glycemic control was also an effect of disease progression, insulin avoidance, side effects of therapy (mainly hypoglycemia and weight gain), and therapeutic inertia on the part of clinicians [11,12]. Other study described the following factors, related to therapy, patient knowledge, psychosocial factors and occupation, induced uncontrolled blood glucose. This paper reports on findings from interviews which were conducted to describe the MRPs of people with T2DM. Psychological factors, particularly negative emotions (i.e., anger and fear) and cumulative negative experiences affect the patient's glycemic control [11].

The results of the interview showed that those who worked outside their home had a higher level of stress than those who were retired or did not work. The patients with poor control glycemic were not burdened by treatment or illness severity enhancement, as mentioned by Tanenbaum et al. [13]. Their comprehensive knowledge and experience in diabetes were very influential in stress management. Indelicato et al. reported that the lower self-efficacy and the higher diabetes distress, the poorer glycemic control [14].

Smoking is associated with insulin resistance; meanwhile, it has not been reported that it can elevate HbA1c significantly in type 2 diabetics.
Smoking cessation is often occurred with weight gain, and obesity is a risk factor of T2DM [15].

The previous study found that forgetfulness was significantly associated with drug-related problems [16]; nevertheless, the participants rarely miss their medication.

\section{CONCLUSIONS}

The medication therapy targets in T2DM not be met were not only caused by the inappropriate use of drugs, but also by patients' lifestyle and psychosocial problems. Pharmacists need to consider the most common MTPs when counseling patients with T2DM.

\section{ACKNOWLEDGMENTS}

The authors are very grateful to all patients interviewed. We would like to appreciate the doctors, pharmacist, and nursing staff of outpatient department for their contribution to this study. This research is part of dissertation project supported by a grant from Indonesian Ministry of Research, Technology, and Higher Education.

\section{REFERENCES}

1. World Health Organization. Diabetes Country Profiles 2016. WHO; 2016. Available from: http://www.who.int/diabetes/country-profiles/en.

2. American Diabetes Association. Standards of medical care in diabetes-2016: Summary of revisions. Diabetes Care 2016;39 Suppl 1:S4-5. Available from: http://www.care. diabetesjournals.org/content/39/Supplement_1/S4.

3. Adusumilli P, Adepu R. Drug-related problems - An overview of various classification systems. Asian J Pharm Clin Res 2014:7(4):7-10.

4. Haugbølle LS, Sørensen EW. Drug-related problems in patients with angina pectoris, Type 2 diabetes and asthma - Interviewing patients at home. Pharm World Sci 2006;28(4):239-47.

5. Zaman Huri H, Chai Ling L. Drug-related problems in Type 2 diabetes mellitus patients with dyslipidemia. BMC Public Health 2013;13:1192

6. Wahyuningrum R, Wahyono D, Mustofa M, Prabandari YS. Medication-related problems in patients with Type 2 diabetes: A Qualitative interviews. In: Proceeding Book International Conference Cardiovascular Diseases (CVD-IA): Integrated Approach from Basic, Clinical Science, Public Healthh and Bioethics. Yogyakarta: Fakultas Kedokteran Universitas Islam Indonesia; 2016. p. 189-200. Available from: http://www.cvd-ia.uii.ac.id/wp-content/uploads/ProceedingInternational-Conference-Book.pdf.

7. Whiting DR, Guariguata L, Weil C, Shaw J. IDF diabetes atlas: Global estimates of the prevalence of diabetes for 2011 and 2030. Diabetes Res Clin Pract 2011;94(3):311-21.

8. Badan Litbangkes. Hasil Riset Kesehatan Dasar (Riskesdas) 2013. Jakarta: Kementerian Kesehatan Republik Indonesia; 2013.

9. Roozendaal BW, Krass I. Development of an evidence-based checklist for the detection of drug related problems in Type 2 diabetes. Pharm World Sci 2009;31(5):580-95.

10. Wiener ES, Mullins CD, Pincus KJ. A framework for pharmacistassisted medication adherence in hard-to-reach patients. Res Soc Adm Pharm 2015;11(5):595-601.

11. Khan H, Lasker SS, Chowdhury TA. Exploring reasons for very poor 
glycaemic control in patients with Type 2 diabetes. Prim Care Diabetes 2011;5(4):251-5

12. Asmini P. the influence of education of drug information by pharmacist on the improvement of knowledge and therapeutic target to Type 2 diabetes mellitus outpatients in hospital. Int $\mathrm{J}$ Pharm Pharm Sci 2017;9(3):199.

13. Tanenbaum ML, Kane NS, Kenowitz J, Gonzalez JS. Diabetes distress from the patient's perspective: Qualitative themes and treatment regimen differences among adults with Type 2 diabetes. J Diabetes
Complications 2016;30(6):1060-8

14. Indelicato L, Dauriz M, Santi L, Bonora F, Negri C, Cacciatori V, et al. Psychological distress, self-efficacy and glycemic control in Type 2 diabetes. Nutr Metab Cardiovasc Dis 2017;27(4):300-6.

15. Sapkota NK. Glycemic control in smokers and risk of Type 2 diabetes. Innov J Health Sci 2016;4(5):1-2.

16. Appalasamy J, Sarriff A. A survey of drug-related problems among patients treated for allergy symptoms in community pharmacies at Negeri Sembilan, Malaysia. Int J Pharm Pharm Sci 2014;6(10):313-6. 